\section{Neighborhood social environment and disability among Mexican older adults: a cohort-based analysis}

\author{
O ambiente social da vizinhança e a incapacidade \\ nos idosos mexicanos: uma análise de coorte
}

\author{
Ambiente social del vecindario y discapacidad \\ entre adultos mayores mejicanos: un análisis \\ basado en cohortes
}

Laura Juliana Bonilla-Tinoco 1 Julián Alfredo Fernández-Niño 2 Dustin T. Duncan ${ }^{3}$

doi: 10.1590/0102-311X00206919

\begin{abstract}
Considering that the world population is rapidly aging and disability is a very frequent event in older adults, there is an increasing interest in studying their determinants, such as the neighborhood characteristics. Thus, this study aimed to explore the association between the social environment of the neighborhood and disability in older adults. A cohort study was assembled using waves 1 and 2 from the Study of Global Ageing and Adults Health (SAGE) in Mexico, which included adults with 55+ years old. Neighborhood characteristics - such as social participation, trust and safety - and individual covariates were measured only in wave 1 (baseline), while disability was measured in both waves to adjust for the score of wave 1. Multilevel negative binomial models with random intercepts at the municipality level were constructed for the disability score in wave 2, using each of the social environment variables as the main exposure and adjusting for the sociodemographic and health-related variables. Finally, interaction terms with sex, age, and socioeconomic quintiles were tested. Results showed that neighborhoods with a medium (IRR: 0.68; 95\%CI: 0.53-0.87) or high (IRR: 0.67; 95\%CI: 0.52-0.86) safety level were associated with a significant reduction in the disability score of adults older than 75 years, although there was no association between other characteristics of the social environment and disability in the general sample. Consequently, actions to improve safety in the neighborhoods should be carried out to help reduce the disability score in vulnerable older adults, especially in a context where safety is a critical issue, as in Mexico.
\end{abstract}

Disabled Persons; Aged; Spatial Regression; Cohort Studies;

Social Environment

\author{
Correspondence \\ J. A. Fernández-Niño \\ Universidad del Norte. \\ Km 5, Via Puerto Colombia, Barranquilla / Atlántico - 080001 , \\ Colombia. \\ aninoj@uninorte.edu.co \\ 1 Universidad Industrial de Santander, Bucaramanga, \\ Colombia. \\ 2 Universidad del Norte, Barranquilla, Colombia. \\ 3 Columbia University Mailman School of Public Health, New \\ York, U.S.A.
}




\section{Introduction}

The worldwide prevalence of disability in people 18 and older was reported as 15.6\% in 20041. However, the figures were higher in vulnerable populations, such as women (19.2\%), people from the poorest socioeconomic quintile (20.7\%) and older adults (38.1\% in individuals over 60 years) ${ }^{1}$. Furthermore, in the 1990-2017 period, the global burden of disability increased by $52 \%$ and although the global health improved throughout this period, the disability adjusted life years (DALYs) remained high in the 50-69 and 70+ year age groups (roughly 50,000 and 100,000 DALYs per 100,000 individuals, respectively) 2. In 2017, 853 million years of healthy life were estimated to be lost worldwide due to disease and disability 2 , with non-communicable diseases causing $80 \%$ of disability ${ }^{3}$. In Mexico, the disability prevalence in the general population has been reported to be $6.6 \%$, with older adults representing $51.4 \%$ of the disabled 4 . As such, disability represents a great burden to society, because it is not only a frequent event that increases individual and public expenditure in health care, rehabilitation, and other services to achieve a reasonable living standard, but it also leads to social exclusion, stress, and loss of productivity of disabled individuals 1 .

The concept of disability has changed over the past decades from a purely medical model to a more holistic approach that incorporates the social perspective as well ${ }^{1}$. Thus, disability can be currently understood as a "dynamic interaction between health conditions and contextual factors, both personal and environmental" 1 (p. 4), which derives in the hindrance of performing social roles 5 . The importance of this definition lies on the recognition of disability as a social process, in which a gap between the environment demands and the individual's ability to respond to them is present 6 .

Considering that disability is a condition that occurs more frequently with increasing age and that the world population is rapidly aging, there is a great interest in studying the factors related to the appearance and course of disability in older adults. Neighborhood characteristics is one of those determinants, since the neighborhood becomes the main environment for older adults, as the number of places where older adults can travel decreases 6,7 . This way, older adults might be more vulnerable to the neighborhood environment not only because of their age-related increased vulnerability, but also because they might have a higher exposure to harmful features of the neighborhood for spending more time in there 6,7. Consequently, part of the actions to address this issue should be directed towards the promotion of "age-friendly" environments that are "supportive of all older adults", so that individuals would be able to preserve their functionality and well-being in old age 8 .

Regarding the studies about the relationship between the neighborhood characteristics and disability in older adults, associations with the neighborhood socioeconomic status and some features of the built environment have been conducted 9,10,11,12,13. Overall, disability has been reported as higher in neighborhoods with low socioeconomic status 9,10, excessive noise and poor lighting 14; and it has been reported as lower in neighborhoods with better connectivity and streets quality 11 . On the other hand, mixed findings have been found regarding the association between social environment (e.g., social capital, neighborhood safety and trust, and some perceived problems, such as crime, noise, litter, etc.) and disability in older adults, since some studies found no association 11,15,16, whereas others describe the negative influence of an unsafe neighborhood on the presence of disability in the elders 17,18 .

Despite the recent raise in researches about the association between the neighborhood characteristics and health outcomes in older adults, investigations evaluating the relationship between neighborhood and disability are still scarce and the available studies have some limitations 10,12,13. For example, it has been reported a high heterogeneity in the measurement of disability and neighborhood characteristics, and a lack of studies using national representative samples, sex-based analysis or longitudinal investigations 11,13 . Furthermore, most research on this topic has been performed in high-income countries and most investigations focus on the association between the built environment and disability 11,12,13,14. Thus, few research are found in low- and middle-income countries and regarding the social environment of the neighborhood and its association (if any) with disability in old age.

Based on the aforementioned, it can be inferred that is necessary to continue the study of the relationship between the neighborhood features (especially social environment) and disability in older adults to be able to successfully respond to the challenges entailed by the population aging and 
to enhance the policy-making process. This is especially important in a scenario such as Mexico, an upper middle-income country where older adults represented 10-19\% of the total population in 2012 and they are expected to be up to $25-29 \%$ by 205019 . Therefore, this study was aimed to examine the association between social environment of the neighborhood and disability in Mexican older adults using a longitudinal methodological approach.

\section{Methods}

\section{Study population}

The Study of Global Ageing and Adults Health (SAGE) is a longitudinal, multi-country study carried out in six low- and middle-income countries: Mexico, South Africa, India, China, Ghana, and Russian Federation. It has multiple waves, such as wave 0, also referred to as the World Health Survey (20022004); wave 1 (2009-2010); and wave 2 (2014). The samples of SAGE were selected by using multistage, cluster-sampling strategies, so that they were nationally representative of people 50 years and older. In Mexico, the sample of wave 1 was composed of a primary sample (all 50+ year wave 0 participants from urban and rural areas, and $90 \%$ of 50+ year wave 0 participants from the metropolitan area), a replacement sample (the remaining $10 \%$ of the $50+$ years adults from the metropolitan area) and a supplementary sample (individuals 50+ years who did not participate in wave 0 , but who shared a household with a member who had participated in it) in case people from the primary sample could not be located or refused to participate. Thus, wave 1 had participants from wave 0 and new participants, so the final sample comprised 5,448 individuals. For wave 2, the sampling procedure was similar, so there were participants from wave 1 and new participants; the final sample was composed of 5,154 subjects. Additionally, both waves had the same 211 primary sampling units. Additional details of the SAGE sampling methodology have been described elsewhere 20,21.

\section{Participants}

This research is a cohort study based upon waves $1(n=5,448)$ and $2(n=5,154)$ from SAGE-Mexico, which used the same individual and household instruments, and collected information about specific neighborhood perceptions. Wave 0 was not considered in this study for its questionnaire is different from that of waves 1 and 2, and it does not use the same questions to assess disability and neighborhood measures. Thus, the cohort was assembled by including those individuals who were 55 years old at wave 1 (which served as the baseline) and also participated in wave 2 (the follow-up). The chosen age criteria allowed including not only people who already were older adults in wave 1, but also those who became older adults during the study period. The above yielded a sample of 1,759 adults, although only 1,187 people $(67.48 \%$ ) composed the analytical sample because they had complete information for the analysis. The 1,187 individuals were distributed in 94 clusters, with a mean of 12.6 people per cluster. Figure 1 shows the conformation of the sample for this study.

\section{Measures}

\section{- Social environment of the neighborhood}

The neighborhood social environment was measured in wave 1 (baseline) by evaluating social participation, trust, and safety in neighborhoods. These variables were created based on the questions from the social cohesion section of the individual questionnaire, as described in previous work 22. Social participation was assessed with four items, which inquired about the frequency of certain social activities. The response options were a 5-point Likert scale ranging from never to daily. The answers to every item were dichotomized into 1 if the answer was once or twice per month or more, and 0 otherwise. The final score was obtained by counting the number of points and it was divided into low (0 points), medium (1 point), and high (2-4 points). 


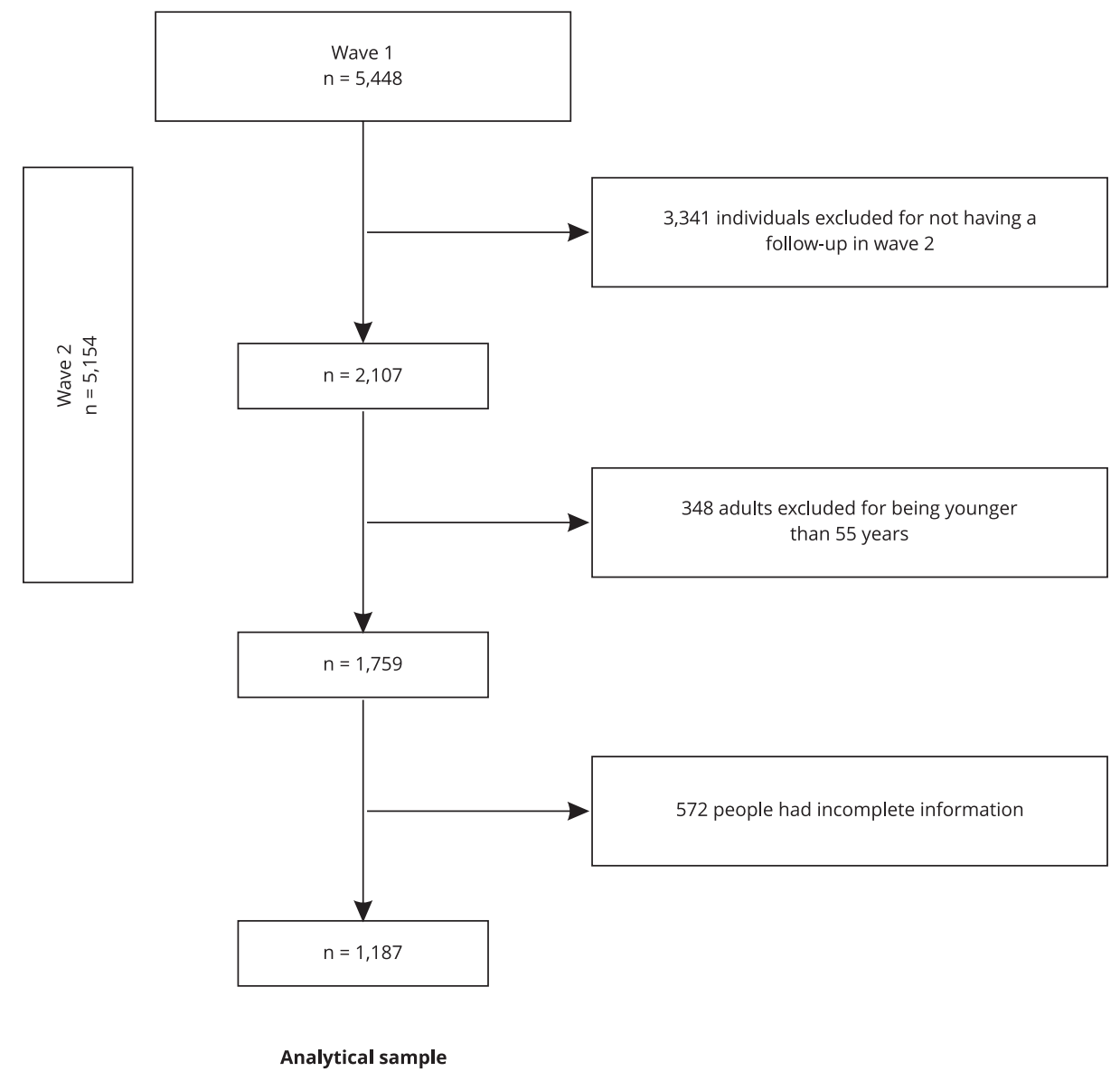

Trust was measured by a question inquiring about the degree of trust the individual had in people from their neighborhood. Response options ranged from "to a very great extent", "to a very small extent". The variable was made dichotomous, so that participants were considered to trust their neighbors if they responded any of the first two options, whereas they were regarded as not trusting people from their neighborhood if the answer was any of the other options.

Lastly, safety was ascertained by two items regarding the level of safety the adult felt when being alone at home and when walking down the street alone in the dark. Answer options ranged from "completely safe" to "not safe at all", so that a point was given if the person responded "completely safe" or "very safe". Another question regarding whether the participant or anyone from their household had been victim of a violent crime in the past 12 months was also used. If the answer was positive, a point was given; if the answer was negative, no points were added. Then, the total points were counted and divided into low (0), medium (1), and high (2-4). 


\section{- Disability}

Disability was ascertained in both waves 1 and 2 by applying the 12 -item version of the WHO Disability Assessment Schedule (WHODAS 2.0; https://www.who.int/classifications/icf/whodasii/en/), which was included in SAGE individual questionnaire 20 . This instrument explains $81 \%$ of the variance of the complete 36 -item version and its psychometric properties have been previously described in detail 23. The WHODAS 2.0 evaluates the level of functioning in six domains of the individual's life in the previous 30 days: cognition, mobility, self-care, getting along, life activities, and participation. The questions analyzed the difficulty in the previous 30 days to perform some activities, such as learning a new task, making new friendships, dealing with strangers, standing for long periods, taking care of the household responsibilities, joining community activities, concentrating for 10 minutes, walking long distances, bathing, getting dressed, and daily work. The response options were presented as a Likert scale ranging from 1 (none) to 5 (severe) and the total score was obtained by adding up the punctuation of each item, so that higher scores indicated higher disability ${ }^{23}$. It is worth clarifying that although the outcome of interest, and the one to be modelled in the regression analysis, is disability in wave 2 (follow-up), the disability score was also measured in wave 1 (with the same instrument, as aforementioned) in order to use it as an adjustment covariate in the multivariable analysis. The latter considering that since the WHODAS 2.0 has no established cutoff point that enabled the categorization of disability 23, disabled people could not be excluded from the beginning of the study (as a cohort design indicates), so the chosen alternative was to adjust for the initial disability score.

\section{- Individual-level sociodemographic characteristics}

Variables from the individual level were also considered for analysis. These variables included sex, age groups (55-59, 60-69, 70-79, and 80 and older), marital status (with or without permanent partner), education level, and the individual-level socioeconomic status quintiles. The latter was approached with a wealth index, which was based on the ownership of assets and access to services. Thus, a continuous index was estimated at the household level by using a random effect model; then, this index was divided into quintiles, where the first and fifth quintiles corresponded to the poorest and richest socioeconomic quintiles, respectively 24 . Finally, multimorbidity (yes vs. no) was also included, which was defined as reporting a medical diagnosis of two or more chronic conditions ascertained in the original study (arthritis, stroke, angina, diabetes, chronic lung disease, asthma, depression, hypertension, and cataracts). The covariates considered in the analysis were measured in wave 1 and selected based on previous research 9,11 .

\section{- Neighborhood-level socioeconomic status and area of residence}

The deprivation index at the municipality level was used as proxy for the neighborhood-level socioeconomic status considering that, in Mexico, there is a lack of necessary information to construct this index at the neighborhood level. The deprivation index is a composite measure based on nine socioeconomic indicators: percentage of individuals aged $15+$ who are illiterate or lack elementary school; percentage of households with any level of overcrowding, soil floors, no tap water, no electricity, and no drainage; percentage of individuals earning less than two minimum wages; and percentage of individuals dwelling in communities with less than 5,000 inhabitants. These indicators are summed up in four dimensions: education, household characteristics, work-related income, and rurality, yielding a continuous variable that indicates the extent of marginalization and social exclusion of a specific geographic area. Thus, the continuous variable was divided into quintiles, where the lowest quintile corresponded to a very low deprivation level and the highest quintile, to a very high deprivation level. Details of the construction of this index have been described elsewhere 25. Furthermore, the area of residence (rural or urban) was assessed. 


\section{Statistical analysis}

For the descriptive analysis, central tendency and dispersion measures were used to describe quantitative variables, whereas the categorical ones were described by using proportions and $95 \%$ confidence intervals $(95 \% \mathrm{CI})$. Additionally, graphic methods were used to assess the underlying distribution of disability score in waves 1 and 2. In the bivariate analysis, Mann-Whitney U test, Kruskal-Wallis test, and the Spearman's correlation coefficient were used to assess the bivariate associations between disability score in wave 2 and the categorical and quantitative variables, respectively. Moreover, univariate and bivariate analysis were stratified by sex. For the multivariable analysis, models of multilevel negative binomial regression with random intercepts at the municipality level were used to obtain incidence rate ratios (IRR), since the graphic methods to explore the disability score in wave 2 presented a heavily left-skewed distribution and the numeric methods highlighted overdispersion. The model with random intercepts was chosen since a model with both random intercepts and slopes showed no improvement in the log likelihood of the model and the variance of random slopes of the main independent variables tended to zero. Additionally, it has been described that a random effect estimator is preferred when few observations within the clusters occur, since it is more reliable 26 . Note that the multilevel model was chosen to account for the correlation structure of the analyzed data and to obtain more precise estimates of the confidence intervals; however, this study aims to evaluate the individual-level effects, not to study the effect of the municipality (group-level effect). Different models were constructed for the disability score in wave 2, using each of the social environment variables (i.e., social participation, safety and trust) as the main predictor and adjusting it for the aforementioned covariates.

Lastly, interactions with sex, age, and individual-level socioeconomic status quintiles were tested. For the age interaction, two age groups were created: younger than 75 years old and 75 years old and older, since it has been described that based on the disability point of view, old age starts at 75 years 27 . Similarly, individual-level socioeconomic status quintiles were regrouped into three categories: lowest (quintiles 1 and 2), medium (quintile 3), and highest (quintiles 4 and 5) for the individual-level socioeconomic status interaction. The tested interactions were selected based on previous research that conducted a similar analysis 18 and the differential frequency of disability according to sex, age group, and socioeconomic status 1 . The correct specification of the constructed models was evaluated with residuals examination (using numerical and graphic methods) and the use of linktest; also, the expected values of disability score were predicted based on the models and they were compared with the observed data by the Spearman's correlation test, which is technically equivalent to conducting a goodness-of-fit test. Finally, some sensitivity analyses were carried out: a loss data analysis and an analysis incorporating the complex sampling design of the original study. The first one was performed to assess differential losses of information, which was done by comparing the available data between included and excluded adults and then using hypothesis testing (Fisher's exact test for the categorical variables and the Mann-Whitney $U$ test for the quantitative ones). The second analysis was carried out to ascertain the change in the estimates when considering the individual-level sampling weights from wave 1 . All analysis were performed in Stata 14 (https://www.stata.com) and the significance level was set at 0.05 .

\section{Ethical considerations}

This study uses secondary and public data from SAGE; thus an ethics review board approval was not necessary. However, access to the databases and permission to use them was requested and granted by the WHO Multi-country Studies Data Archive team by the online platform. SAGE was approved by the WHO Ethics Committee and all its participants provided their written informed consent to participate. 


\section{Results}

The analytic sample was composed of 1,187 (67.48\%) individuals who had complete information in all the considered variables. Women represented $60.83 \%$ (95\%CI: 58.01-63.57) of the sample, almost half of the individuals were 60-69 years (46.25\%; 95\%CI: 43.43-49.10), about two thirds had exclusively complete primary school (66.13\%; 95\%CI: 63.39-68.77) and the median disability score in wave 2 was 16 (interquartile range - IQR: 13-23). Regarding the neighborhood characteristics, 80.45\% (95\%CI: 78.10-82.62) of the participants reported a low perception of social participation; $42.97 \%$ of adults trusted their neighbors (95\%CI: 40.17-45.81); and 56.78\% reported a high level of safety (95\%CI: 53.94-59.58). It was found that, compared to women, more men reported low and high levels of social participation (83.66\%; 95\%CI: 79.99-86.76) and safety (58.49\%; 95\%CI: 53.94-62.91), respectively. Similarly, a slightly higher proportion of men reported to trust their neighbors $(45.59 \%$; $95 \% \mathrm{CI}$ : 41.10-50.16) in comparison to women. The complete descriptive analysis is presented in Table 1.

The bivariate analysis showed that none of the neighborhood social environment features was associated with the disability score in wave 2 ; this finding remained when stratifying by sex. Only in men was found a marginal association between municipality deprivation index and the disability score $(\mathrm{p}=0.10)$. On the other hand, all the individual-level predictors were significantly associated with the disability score in the general sample and in men, except for the area of residence in the latter. In the case of women, only the disability score in wave 1, the age group, and the education level showed a significative association.

In the multivariable analysis (Table 2), we found that the medium (IRR: 0.93 ; 95\%CI: 0.86-1.01) level of safety showed a marginal association with a lower disability score in the total sample, which indicates that a medium level or perceived safety of the neighborhood is associated with $7 \%$ reduction in the expected disability score. On the other hand, social participation and trust in neighbors were not associated. As to the individual level variables, the disability score in wave 1, sex, age, area of residence, and multimorbidity were also significantly associated with the disability score in wave 2. In stratified analyses (Tables 3 and 4), adults aged 75 years and older had a significant reduction in their expected disability score when the level of safety of the neighborhood was medium (IRR: 0.68; 95\%CI: 0.53-0.87) or high (IRR: 0.67; 95\%CI: 0.52-0.86) compared to a low level, which corresponds to a decrease of $32 \%$ and $33 \%$, respectively. Contrarily, there was no evidence of a significant interaction with sex or the individual-level socioeconomic status quintiles.

Lastly, the residuals examination showed the expected behavior for a negative binomial model, the linktest indicated a correct specification of the model and the Spearman's correlation test between predicted values and observed data was always above $0.5(\mathrm{p}<0.001)$, which indicates an adequate goodness-of-fit of the used models.

\section{Sensitivity analyses}

The loss data analysis showed that there were differential losses in some covariates used for adjustment in the multivariable analysis, which included individual-level socioeconomic status quintiles, education level, residence area, and age group. Information losses in the main independent variables, i.e. the neighborhood social environment characteristics, were not differential. Furthermore, although the hypothesis testing resulted significant when evaluating differential losses in the disability score from waves 1 and 2 between included and excluded people, the exploratory analysis showed that the former (median score: 16; IQR: 13-23 in both waves) had a very similar median to that of the latter (wave 1 median score: 20; IQR: 15-27; wave 2 median score: 15; IQR: 12-20) in the disability score from both waves.

Regarding the analysis incorporating the complex sampling design of the original study, all models were run again, which showed that the estimates remained very similar to those obtained with the original models that did not account for the sampling weights. The change in all estimates was less than $10 \%$ in all cases and the initial conclusions remained unchanged. 


\section{Table 1}

Neighborhood features and sociodemographic and health-related characteristics of the Mexican older adults from the Study of Global Ageing and Adults Health (SAGE). Mexico, 2009-2014.

\begin{tabular}{|c|c|c|c|}
\hline Characteristics & $\begin{array}{c}\text { Total }(n=1,187) \\
\%(95 \% \mathrm{Cl})\end{array}$ & $\begin{array}{c}\text { Men }(n=465) \\
\%(95 \% \mathrm{Cl})\end{array}$ & $\begin{array}{c}\text { Women }(n=722) \\
\%(95 \% \mathrm{Cl})\end{array}$ \\
\hline \multicolumn{4}{|l|}{ Outcome } \\
\hline Disability score * [median (IQR)] & $16(13-23)$ & $15(13-20)$ & $18(13-24)$ \\
\hline \multicolumn{4}{|l|}{ Neighborhood level } \\
\hline \multicolumn{4}{|l|}{ Social participation } \\
\hline Low & $80.45(78.10-82.62)$ & 83.66 (79.99-86.76) & $78.39(75.23-81.25)$ \\
\hline Medium & $12.30(10.55-14.30)$ & $10.32(7.86-13.45)$ & $13.57(11.26-16.28)$ \\
\hline High & $7.25(5.90-8.87)$ & $6.02(4.18-8.59)$ & $8.03(6.26-10.26)$ \\
\hline \multicolumn{4}{|l|}{ Safety } \\
\hline Low & $5.31(4.17-6.74)$ & $4.52(2.96-6.84)$ & $5.82(4.32-7.78)$ \\
\hline Medium & $37.91(35.19-40.71)$ & $36.99(32.70-41.49)$ & $38.50(35.01-42.12)$ \\
\hline High & $56.78(53.94-59.58)$ & $58.49(53.94-62.91)$ & $55.68(52.02-59.27)$ \\
\hline \multicolumn{4}{|l|}{ Trust in neighbors } \\
\hline Yes & $42.97(40.17-45.81)$ & $45.59(41.10-50.16)$ & $41.27(37.73-44.91)$ \\
\hline \multicolumn{4}{|l|}{ Socioeconomic status (deprivation index) } \\
\hline Very low & $65.96(63.22-68.61)$ & $63.23(58.73-67.50)$ & $67.73(64.22-71.05)$ \\
\hline Low & $18.79(16.66-21.11)$ & $18.49(15.21-22.30)$ & $18.98(16.27-22.01)$ \\
\hline Medium & $6.15(4.92-7.67)$ & $7.10(5.08-9.83)$ & $5.54(4.09-7.47)$ \\
\hline High & $8.00(6.59-9.69)$ & $10.32(7.86-13.45)$ & $6.51(4.92-8.56)$ \\
\hline Very high & $1.10(0.64-1.88)$ & $0.86(0.32-2.28)$ & $1.25(0.65-2.38)$ \\
\hline \multicolumn{4}{|l|}{ Individual level } \\
\hline Disability score in wave 1 [median (IQR)] & $16(13-23)$ & $15(13-21)$ & $17.5(14-24)$ \\
\hline Multimorbidity & $33.11(30.48-35.84)$ & $26.88(23.03-31.11)$ & $37.12(33.66-40.71)$ \\
\hline Female sex & $60.83(58.01-63.57)$ & - & - \\
\hline \multicolumn{4}{|l|}{ Age group (years) } \\
\hline $55-59$ & $18.70(16.58-21.03)$ & $18.92(15.61-22.76)$ & $18.56(15.88-21.57)$ \\
\hline $60-69$ & $46.25(43.43-49.10)$ & $46.24(41.73-50.80)$ & $46.26(42.64-49.92)$ \\
\hline $70-79$ & $28.56(26.06-31.20)$ & $28.60(24.66-32.90)$ & $28.53(25.35-31.94)$ \\
\hline $80+$ & $6.49(5.22-8.04)$ & $6.24(4.36-8.84)$ & $6.65(5.04-8.72)$ \\
\hline \multicolumn{4}{|l|}{ Marital status } \\
\hline Has permanent partner & $63.86(61.08-66.55)$ & $81.72(77.93-84.99)$ & 52.35 (48.70-55.99) \\
\hline \multicolumn{4}{|l|}{ Education level } \\
\hline No schooling & $16.60(14.58-18.83)$ & $10.97(8.42-14.16)$ & $20.22(17.44-23.32)$ \\
\hline Complete elementary & $66.13(63.39-68.77)$ & $71.61(67.33-75.54)$ & $62.60(59.00-66.07)$ \\
\hline Complete high school & $8.59(7.13-10.33)$ & $11.18(8.61-14.40)$ & $6.93(5.28-9.03)$ \\
\hline Complete higher education & $8.68(7.20-10.42)$ & $6.24(4.36-8.84)$ & $10.25(8.23-12.69)$ \\
\hline Urban area of residence & 73.55 (70.96-75.98) & $67.74(63.34-71.85)$ & $77.29(74.08-80.20)$ \\
\hline \multicolumn{4}{|l|}{ Socioeconomic status (quintiles) } \\
\hline 1 & $20.05(17.87-22.43)$ & $19.14(15.80-22.99)$ & $20.64(17.83-23.75)$ \\
\hline 2 & $20.89(18.67-23.30)$ & $18.71(15.41-22.53)$ & $22.30(19.40-25.49)$ \\
\hline 3 & $17.78(15.70-20.06)$ & $15.48(12.46-19.08)$ & $19.25(16.53-22.30)$ \\
\hline 4 & $22.33(20.04-24.79)$ & $26.02(22.22-30.22)$ & $19.94(17.18-23.03)$ \\
\hline 5 & $18.96(16.82-21.29)$ & 20.65 (17.20-24.58) & $17.87(15.24-20.84)$ \\
\hline
\end{tabular}

95\%Cl: 95\% confidence interval; IQR: interquartile range.

* Disability score measured in wave 2 . 
Table 2

Multivariable analysis of the association between the disability score and the social environment of the neighborhood in Mexican older adults from Study of Global Ageing and Adults Health (SAGE). Mexico, 2009-2014.

\section{Disability score in wave 2}

\section{Characteristic}

Total $(n=1,187)$

IRR $(95 \% \mathrm{Cl})$

$\begin{array}{lc}\text { Neighborhood level } & \\ \text { Social participation } & \\ \text { Low } & \text { Reference } \\ \text { Medium } & 0.99(0.93-1.04) \\ \text { High } & 0.96(0.90-1.02) \\ \text { Safety } & \\ \text { Low } & \text { Reference } \\ \text { Medium } & 0.93(0.86-1.01) \text { * } \\ \text { High } & 0.94(0.88-1.02) \\ \text { Trust in neighbors } & \\ \text { No } & \text { Reference } \\ \text { Yes } & 0.99(0.96-1.03)\end{array}$

95\% Cl: 95\% confidence interval; IRR: incidence rate ratios.

Note: Estimates adjusted for disability score in wave 1, sex, age, marital status, educational level, area of residence, multimorbidity, individual socioeconomic status, deprivation index at the municipality level. Municipality level used as clusters.

* $p<0.10$.

\section{Table 3}

Interaction analysis of the social environment of the neighborhood with sex and age in Mexican older adults from Study of Global Ageing and Adults Health (SAGE). Mexico, 2009-2014.

\section{Disability score in wave 2}

\begin{tabular}{|c|c|c|c|c|}
\hline \multirow[t]{3}{*}{ Characteristic } & \multicolumn{2}{|c|}{ Sex } & \multicolumn{2}{|c|}{ Age (years) } \\
\hline & Men $(n=465)$ & Women $(n=722)$ & $<75(n=959)$ & $75+(n=228)$ \\
\hline & IRR $(95 \% \mathrm{Cl})$ & IRR $(95 \% \mathrm{CI})$ & IRR (95\%Cl) & IRR (95\%Cl) \\
\hline \multicolumn{5}{|c|}{ Neighborhood level } \\
\hline \multicolumn{5}{|c|}{ Social participation } \\
\hline Low & Reference & Reference & Reference & Reference \\
\hline Medium & $1.01(0.92-1.11)$ & $0.98(0.91-1.05)$ & $0.98(0.93-1.03)$ & $0.97(0.81-1.16)$ \\
\hline High & $1.00(0.91-1.10)$ & $0.93(0.85-1.02)$ & $0.96(0.89-1.04)$ & $0.91(0.80-1.04)$ \\
\hline \multicolumn{5}{|l|}{ Safety } \\
\hline Low & Reference & Reference & Reference & Reference \\
\hline Medium & $0.90(0.76-1.06)$ & $0.95(0.86-1.04)$ & $0.95(0.88-1.03)$ & $0.68(0.53-0.87)$ * \\
\hline High & $0.88(0.75-1.04)$ & $0.97(0.88-1.07)$ & $0.97(0.89-1.04)$ & $0.67(0.52-0.86)$ * \\
\hline \multicolumn{5}{|c|}{ Trust in neighbors } \\
\hline No & Reference & Reference & Reference & Reference \\
\hline Yes & $0.98(0.92-1.04)$ & $1.00(0.96-1.05)$ & $0.99(0.96-1.02)$ & $1.00(0.90-1.11)$ \\
\hline
\end{tabular}

95\%Cl: 95\% confidence interval; IRR: incidence rate ratios.

Note: Estimates adjusted for disability score in wave 1, sex (in the age-stratified models), age (in the sex-stratified models), marital status, educational level, area of residence, multimorbidity, individual socioeconomic status (in the sex and age-stratified models), and deprivation index at the municipality level. Municipality level used as clusters. $* p<0.05$. 
Table 4

Interaction analysis of the social environment of the neighborhood with the individual-level socioeconomic stataus in Mexican older adults from Study of Global Ageing and Adults Health (SAGE). Mexico, 2009-2014.

\begin{tabular}{|c|c|c|c|}
\hline \multicolumn{4}{|c|}{ Disability score in wave 2} \\
\hline \multirow[t]{3}{*}{ Characteristic } & \multicolumn{3}{|c|}{ Socioeconomic quintiles } \\
\hline & Q1 ( $n=486)$ & Q2 (n = 211) & Q3 (n = 490) \\
\hline & IRR (95\%CI) & IRR (95\%CI) & IRR (95\%CI) \\
\hline \multicolumn{4}{|c|}{ Neighborhood level } \\
\hline \multicolumn{4}{|c|}{ Social participation } \\
\hline Low & Reference & Reference & Reference \\
\hline Medium & 0.99 (0.91-1.09) & $0.92(0.81-1.04)$ & $0.99(0.91-1.08)$ \\
\hline High & $0.91(0.82-1.00)$ * & $0.96(0.86-1.06)$ & $1.02(0.92-1.14)$ \\
\hline \multicolumn{4}{|l|}{ Safety } \\
\hline Low & Reference & Reference & Reference \\
\hline Medium & $0.87(0.74-1.02)$ * & $0.88(0.68-1.13)$ & $1.01(0.91-1.12)$ \\
\hline High & $0.88(0.75-1.03)$ & $0.91(0.71-1.18)$ & $1.00(0.92-1.09)$ \\
\hline \multicolumn{4}{|c|}{ Trust in neighbors } \\
\hline No & Reference & Reference & Reference \\
\hline Yes & $1.04(0.99-1.10)$ & $0.95(0.87-1.04)$ & $0.96(0.90-1.03)$ \\
\hline
\end{tabular}

95\% Cl: 95\% confidence interval; IRR: incidence rate ratios.

Note: Estimates adjusted for disability score in wave 1, sex, age, marital status, educational level, area of residence, multimorbidity, and deprivation index at the municipality level. Municipality level used as clusters. $\star p<0.10$.

\section{Discussion}

This study aimed to explore the association between social environment of the neighborhood and disability in a Mexican older adults, finding that higher safety levels of the neighborhood significantly reduced the disability score in adults aged 75 years and older. Thus, this research complements the current knowledge about the groups of older adults more vulnerable to perceived safety in the neighborhood 17,18. Nonetheless, it also differs from other studies that have found no association 15,16.

The main finding might be explained considering Lawton's ecological model of aging (EMA) and its extension 7. The EMA is a person-environment fit model that states that a balance between environmental press (demands exerted by the environment) and competence ("individual's capacity to function") results in an adaptive behavior, while a maladaptive behavior occurs when any of the two components is lacking or in excess 7,28. Moreover, it states that "the less competent the individual is, the greater the impact of environmental factors" 28 (p. 451). Since aging is associated with a decrease in physiologic reserve, that becomes more evident at older ages, the last EMA consideration might explain why the oldest adults (75 years and older) displayed a greater benefit from neighborhoods with higher safety levels. This age group can be deemed more vulnerable because their competence is diminished, so that a reduction in environmental press results more beneficial for them compared to younger older adults.

Furthermore, neighborhood safety might also influence disability of 75 year and older adults with social contact, since it has been reported that older adults from neighborhoods with adverse conditions tend to distrust their neighbors, so they isolate themselves from the community 7 . Additionally, the relation between disability and safety perception of the neighborhood could also be explained by the promotion of physical activity, inasmuch as the latter has been associated with neighborhood safety 29,30,31,32 and functionality of the older adults 33 .

Neighborhoods across the world can be unsafe, but especially in Mexico, where crime and violence are highly prevalent in all contexts, both public and private, which has led to deem security a 
critical issue 34,35. According to the Mexican National Survey on Victimization and Perception of Public Security (ENVIPE), 66.6\% of Mexican people feel insecure in the region they live in and $71.8 \%$ of the Mexican population indicate insecurity as their main concerning issue. Also, people are refraining from performing certain daily and entertainment-related activities (roughly 30\% of Mexicans have stopped walking outdoor), and they prefer to stay in places they consider safe, such as home 34; which, decreases social cohesion and informal control, promoting social isolation 34,35.

On the other hand, this research has some notably limitations. Firstly, SAGE was designed to be nationally representative, so it does not achieve representativity at lower levels, such as the neighborhood, which is why municipality was selected as the second level of aggregation instead of neighborhood. This situation also caused our primary sampling unit (PSU) to be different from the PSU used in SAGE to estimate the sampling weights, which is why they were not included in the main analyses. Moreover, the sensitivity analysis showed little variation in the estimates when including this weights (so the conclusions did not change); the additional analyses accounted for the aggregation structure of data; and the residuals examination, as well as the assessment of the models' specification and goodness-of-fit, indicated the adjusted models were adequate. Secondly, neighborhood safety was measured subjectively by the perceived safety of each participant instead of an objective measure, such as the neighborhood crime rate, since this latter information was not available. This could introduce an information bias because disabled people could be more aware of their environment and tend to perceive their neighborhood as more unsafe than non-disabled do. However, this possibility is thought to be unlikely for exploratory analysis presented a very similar median disability score in all levels of perceived safety of the neighborhood. Thirdly, the neighborhood was not defined by an objective measure, such as administrative boundaries, egocentric buffers or global positioning system (GPS) measurements, but rather it was self-defined by each individual. Thus, the neighborhood measure was not standardized, so each participant might have had a different definition of it depending on their perception 36 , which could influence the association between social environment and disability. Nevertheless, it has been reported that neighborhood definitions that are exposure or outcome-related (such as in this case) could reduce the within-variance and increase the betweenvariance and such definitions not based on administrative or statistical units might better capture the subjective meaning of neighborhood 37 . In the fourth place, the response rate at baseline (wave 1) was $53 \%$, which decreased the sample available for analysis and resulted in a reduction of the analytical sample of a little over $30 \%$, which could lead to selection bias. Nonetheless, those losses are considered as random, since the reason for low response rate was the inability to locate and to revisit participants 20 . Furthermore, the sensitivity analysis for the loss data showed that differential losses occurred in the adjustment covariates, whose association measure is not the focus of this study; on the other hand, the main independent variables (social environment of the neighborhood), did not show differential losses. Fifthly, the socioeconomic status measurement of the neighborhood had to be estimated for a higher level (the municipality) because that information was not available for the neighborhoods. Notwithstanding, municipality is one of the lowest administrative levels in Mexico. Also, the main exposure, i.e. the social environment of the neighborhood, was measured only in the baseline, which did not allow for the detection of any potential change in it during the study period. However, it is reasonable to assume that most neighborhoods did not suffer considerable changes in a span of a few years, such as the period between waves 1 and 2 ( 4 years). Lastly, since the WHODAS 2.0 simple scoring system was used, there are some significant precautions to be mentioned about the obtained summary score, such as considering that it is specific to the analyzed sample, that is, it cannot be compared across different populations 23 . However, the simple scoring system was chosen for it is a more practical way of measure this variable while it is still valid and because the interpretation of a score that is simply the sum of the raw data might be easier in some contexts. Besides, the WHODAS 2.0 manual indicates that the summary score obtained in the simple scoring method is "sufficient to reflect the degree of functional impairment" 23 (p. 41).

On the other hand, the strengths of this study include its longitudinal design; the use of a nationally representative sample; the low- and middle-income country where it was carried out, since most studies of this kind are conducted in high-income countries; and the ascertainment of different aspects of the social environment, including social participation. Additionally, other strengths are the usage of the same instrument to measure disability in both waves and the possibility to adjust the 
disability score at baseline (wave 1) and the stratification of the analysis by several important variables, enabling the assessment of interactions. Finally, the use of a valid and robust instrument, such as WHODAS 2.0, whose good psychometric properties have been well documented.

In conclusion, higher levels of neighborhood safety reduce the disability score in adults aged 75 years and older, and they might even be beneficial for overall older adults. This finding becomes especially relevant in the Mexican context, where insecurity has been deemed a public problem and where the population is rapidly ageing. Thereby, actions to improve safety in the neighborhoods, such as greater police control or community-police contact to reduce crime and violence, and public lighting maintaining or enhancement, could be implemented at all decision-making levels: from community organizations (boards or councils), to the local, regional or national governments.

\section{Contributors}

L. J. Bonilla-Tinoco contributed to the study design, data analysis, and article drafting and reviewing. J. A. Fernández-Niño contributed to the data analysis and manuscript revision. D. T. Duncan contributed to the manuscript drafting and reviewing.

\section{Additional informations}

ORCID: Laura Juliana Bonilla-Tinoco (0000-00027375-890X); Julián Alfredo Fernández-Niño (00000002-8948-8481); Dustin T. Duncan (0000-00018586-8711).

\section{References}

1. World Health Organization. World report on disability. Geneva: World Health Organization/World Bank; 2011.

2. Roser M, Ritchie H. Burden of disease. https://ourworldindata.org/burden-ofdisease\#citation (accessed on 07/Feb/2020).

3. Institute for Health Metrics and Evaluation. Findings from the Global Burden of Disease Study 2017. Seattle: Institute for Health Metrics and Evaluation; 2018.

4. Gobierno de los Estados Unidos Mexicanos. Programa Nacional para el Desarrollo y la Inclusión de las Personas con Discapacidad. Diario Oficial de la Federación 2014; 30 apr.

5. Nagi SZ. An epidemiology of disability among adults in the United States. Milbank Mem Fund Q Health Soc 1976; 54:439-67.

6. Verbrugge LM, Jette AM. The disablement process. Soc Sci Med 1994; 38:1-14.

7. Glass TA, Balfour JL. Neighborhoods, ageing and functional limitations. In: Kawachi I, Berkman LF, editors. Neighborhoods and health. New York: Oxford University Press; 2003. p. 303-34.

8. United Nations. Political declaration and Madrid International Plan of Action on Ageing. Madrid: United Nations; 2002.

9. Philibert MD, Pampalon R, Hamel D, Daniel M. Associations between disability prevalence and local-area characteristics in a general community-living population. Rev Epidemiol Sante Publique 2013; 61:463-74.

10. Beard JR, Blaney S, Cerda M, Frye V, Lovasi GS, Ompad D, et al. Neighborhood characteristics and disability in older adults. J Gerontol B Psychol Sci Soc Sci 2009; 64:252-7. 
11. Freedman VA, Grafova IB, Schoeni RF, Rogowski J. Neighborhoods and disability in later life. Soc Sci Med 2008; 66:2253-67.

12. Philibert M, Pampalon R, Daniel M. Conceptual and operational considerations in identifying socioenvironmental factors associated with disability among community-dwelling adults. Int J Environ Res Public Health 2015; 12:3814-34.

13. Danielewicz AL, dos Anjos JC, Bastos JL, Boing $\mathrm{AC}$, Boing AF. Association between socioeconomic and physical/built neighborhoods and disability: a systematic review. Prev Med 2017; 99:118-27.

14. Garin N, Olaya B, Miret M, Ayuso-Mateos JL, Power M, Bucciarelli P, et al. Built environment and elderly population health: a comprehensive literature review. Clin Pract Epidemiol Ment Health 2014; 10:103-15.

15. Balfour JL, Kaplan GA. Neighborhood environment and loss of physical function in older adults: evidence from the Alameda County Study. Am J Epidemiol 2002; 155:507-15.

16. Bowling A, Stafford M. How do objective and subjective assessments of neighbourhood influence social and physical functioning in older age? Findings from a British Survey of Ageing. Soc Sci Med 2007; 64:2533-49.

17. Sun VK, Cenzer IS, Kao H, Ahalt C, Williams BA. How safe is your neighborhood? Perceived neighborhood safety and functional decline in older adults. J Gen Intern Med 2011; 27:541-7.

18. Clark CR, Kawachi I, Ryan L, Ertel K, Fay ME, Berkman LF. Perceived neighborhood safety and incident mobility disability among elders: the hazards of poverty. BMC Public Health 2009; 9:1-15.

19. United Nations Population Fund; HelpAge International. Ageing in the twenty-first century: a celebration and a challenge. New York: United Nations Population Fund/London: HelpAge International; 2012.

20. Kowal P, Chatterji S, Naidoo N, Biritwum R, Fan W, Lopez Ridaura R, et al. Data resource profile: the World Health Organization Study on global AGEing and adult health (SAGE). Int J Epidemiol 2012; 41:1639-49.

21. World Health Organization. Study on Global Ageing and Adult Health-2014, Wave 2. Mexico, 2014. http://apps.who.int/healthinfo/sys tems/surveydata/index.php/catalog/212\#pag $\mathrm{e}=$ sampling\&tab $=$ study-desc (accessed on 03 / $\mathrm{Feb} / 2020$ )

22. Ramlagan S, Peltzer K, Phaswana-Mafuya N. Social capital and health among older adults in South Africa. BMC Geriatr 2013; 13:100.

23. Üstün TB, Kostanjsek N, Chatterji S, Rehm J. Measuring health and disability: manual For WHO Disability Assessment Schedule (WHODAS 2.0). Geneva: World Health Organization; 2010.

24. Ferguson BD, Tandon A, Gakidou E, Murray CJL. Estimating permanent income using indicator variables. http://cdrwww.who.int/en tity/healthinfo/paper44.pdf (accessed on 21) $\mathrm{Feb} / 2020$ ).
25. Almejo R, Téllez Y, López J. Índice Absoluto de Marginación 2000-2010. México DF: Consejo Nacional de Población; 2013.

26. Clark P, Crawford C, Steele F, Vignoles A. The choice between fixed and random effects models: some considerations for educational research. Bonn: Institute for the Study of Labor; 2010.

27. Heikkinen E. What are the main risk factors for disability in old age and how can disability be prevented? Copenhagen: WHO Regional Office for Europe; 2003.

28. Cavanaugh JC. Where we live. In: Thomas T, Sanders MZ, Pruno K, editors. Adult development and ageing. 3rd Ed. Pacific Grove: Brooks/Cole Publishing Company; 1997. p. 450-86.

29. Wang Z, Lee C. Site and neighborhood environments for walking among older adults. Health Place 2010; 16:1268-79.

30. Tucker-Seeley RD, Subramanian SV, Li Y, Sorensen G. Neighborhood safety, socioeconomic status, and physical activity in older adults. Am J Prev Med 2009; 37:207-13.

31. Corseuil WM, Hallal PC, Corseuil HX, Schneider IJC, D'Orsi E. Safety from crime and physical activity among older adults: a populationbased study in Brazil. J Environ Public Health 2012; 2012:641010.

32. Won J, Lee C, Forjuoh SN, Ory MG. Neighborhood safety factors associated with older adults' health-related outcomes: a systematic literature review. Soc Sci Med 2016; 165:17786.

33. Mullen SP, McAuley E, Satariano WA, Kealey M, Prohaska TR. Physical activity and functional limitations in older adults: the influence of self-efficacy and functional performance. J Gerontol B Psychol Sci Soc Sci 2012; 67:35461.

34. Jasso López C. Percepción de inseguridad en México. Revista Mexicana Opinión Pública 2013; 15:13-29.

35. Ávila ME, Martínez-Ferrer B, Vera A, Bahena A, Musitu G. Victimization, perception of insecurity, and changes in daily routines in Mexico. Rev Saúde Pública 2016; 50:60.

36. Duncan DT, Regan SD, Chaix B. Operationalizing neighborhood definitions in health research: spatial misclassification and other issues. In: Duncan DT, Kawachi I, editors. Neighborhoods and health. 2nd Ed. New York: Oxford University Press; 2018. p. 19-56.

37. Julien D, Richard L, Gauvin L, Kestens Y. Neighborhood characteristics and depressive mood among older adults: an integrative review. Int Psychogeriatr 2012; 24:1207-25. 


\section{Resumen}

Considerando que la población mundial está envejeciendo rápidamente y la discapacidad es un hecho muy frecuente entre la tercera edad, existe un creciente interés por estudiar los determinantes de esta última, así como las características del vecindario. Por lo tanto, el objetivo de este estudio fue investigar la asociación entre el ambiente social del vecindario y la discapacidad en adultos mayores. La cohorte de estudio se formó usando las curvas 1 y 2, procedentes del Estudio Global sobre el Envejecimiento y la Salud del Adulto (SAGE por sus siglas en inglés) en México, que incluyó adultos de 55+ años. Características del vecindario como: participación social, confianza y seguridad, así como las covariables individuales se midieron sólo en la curva 1 (base de referencia), mientras que la discapacidad se midió en ambas curvas para ajustarla a la puntuación de la curva 1. Se realizaron modelos binomiales negativos multinivel con intercepciones aleatorias en el nivel municipal para el marcador de discapacidad en la curva 2, usando cada una de las variables socioambientales como las de principal exposición y ajustándolas a las variables sociodemográficas, así como a las relacionadas con la salud. Finalmente, se probaron los términos de interacción con sexo, edad, así como quintiles socioeconómicos. Los resultados mostraron que los vecindarios con una media (IRR: 0,68; IC95\%: 0,53-0,87) o alto (IRR: 0,67; IC95\%: 0,52$0,86)$ nivel de seguridad estuvieron asociados con una significativa reducción en el marcador de discapacidad de adultos $75+$ años, pese a que no hubo asociación entre otras características del ambiente social y discapacidad en la muestra general. Consecuentemente, las acciones para mejorar la seguridad en los vecindarios deberían haber ayudado a reducir la puntuación en discapacidad en ancianos vulnerables, especialmente, en un contexto donde la seguridad es un asunto crítico, como en México.

Personas con Discapacidad; Anciano; Regresión Espacial; Estudios de Cohortes; Medio Social

\section{Resumo}

Considerando o envelhecimento rápido da população mundial e o fato de a incapacidade ser um evento muito frequente nos idosos, há um interesse cada vez maior no estudo dos determinantes da incapacidade, que incluem as características da vizinhança. Portanto, o estudo procurou explorar a associação entre o ambiente social da vizinhança e a incapacidade nos idosos. Foi organizado um estudo de coorte com as ondas 1 e 2 do Estudo sobre Envelhecimento Global e Saúde do Adulto (SAGE) no México, que incluiu adultos com 55 anos ou mais. As características da vizinhança, tais como a participação social, confiança e segurança, e as covariáveis individuais foram medidas apenas na onda 1 (linha de base), enquanto a incapacidade era medida em ambas as ondas para ajustar para a pontuação da onda 1. Foram construídos modelos binomiais negativos multiníveis com interceptos no nível municipal para a pontuação da incapacidade na onda 2, usando cada uma das variáveis ambientais como a principal variável de exposição, e ajustando para as variáveis sociodemográficas e sanitárias. Finalmente, foram testados termos de interação com se$x$, idade e quintis socioeconômicos. Os resultados mostraram que os bairros com nivel de segurança médio (RTI: 0,68; IC95\%: 0,53-0,87) ou alto (RTI: 0,67; IC95\%: 0,52-0,86) estavam associados com uma redução significativa na escala de incapacidade nos idosos com 75 anos ou mais, embora não houvesse associação entre outras características do entorno e a incapacidade na amostra geral. Portanto, são necessárias medidas para melhorar a segurança dos bairros para ajudar a reduzir a escala da incapacidade nos idosos vulneráveis, principalmente em um contexto onde a segurança é uma questão crítica, como no México.

Pessoas com Deficiência; Idoso; Regressão Espacial; Estudos de Coortes; Meio Social
Submitted on 24/Oct/2019

Final version resubmitted on 24/Apr/2020

Approved on 30/Apr/2020 